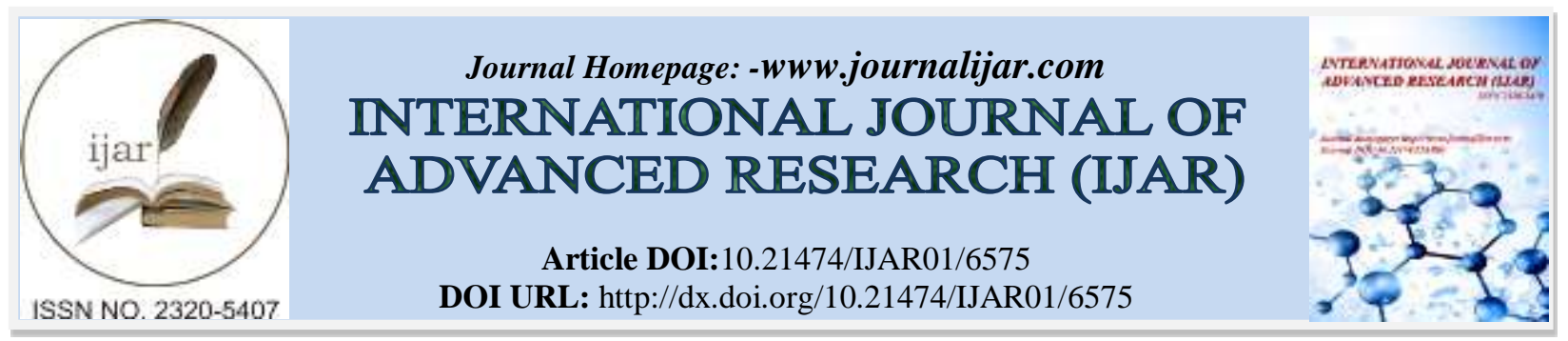

RESEARCH ARTICLE

\title{
KNOWLEDGE AND ATTITUDE OF SAUDI WOMEN TOWARD PAINLESS LABOR, AND MISCONCEPTION ABOUT THE RISKS AND COMPLICATIONS.
}

Dalia Saleh Alsharidah and Fatimah Ibrahim Alhuzaimi.

\section{Manuscript Info}

(.........................

Manuscript History

Received: 18 December 2017

Final Accepted: 20 January 2018

Published: February 2018

\section{Abstract}

Objective: This study aimed to assess the knowledge and attitude of Saudi women toward painless labor, and misconception about the risks and complications.

Method: A cross-sectional study included 386 Saudi woman, was selected randomly. the study conducted using a questionnaire consisted of three sections; the first section was regarding demographic data, while the second section was to assess the women knowledge toward painless labor, and the third section was to assess the women attitude toward painless labor.

Results: $36.7 \%$ availed epidural analgesia in their previous deliveries. 95\% heard about the epidural analgesia to reduce the pain of labor. $50.1 \%$ have positive attitude towards epidural analgesia. $60.9 \%$ did not discuss available birth options with the doctor. $53.9 \%$ preferred natural childbirth as method of birth. $32.1 \%$ will never use any of the anesthetics in their next births.

Conclusion: There was a good level of knowledge and positive attitude towards the epidural analgesia among Saudi women, but there was low prevalence of epidural analgesia using among Saudi women.

Copy Right, IJAR, 2018,. All rights reserved.

\section{Introduction:-}

Most women have exprinsed the most painful pain during vaginal delivery. Those who experienced have described the pain of labor with terms such as distressing, overwhelming, horrible, traumatic or excruciating during the first stage of labor and even worse during the second stage despite its short duration. (1)

Nowadays, the concept of painless labor is ahot topic with a variation on different biological, social, and ethnic characteristics in modern medicine.(2)

There are various methods to painless labor, pharmacological and non- pharmacological treatments protocols are used to relieve labor pain such as opioids, epidural analgesia, hypnosis, or acupuncture.(2)

However, the most effective method for pain less vaginal delivery is Epidural Analgesia, which is a technique of injecting a combination of local anesthetic and opioid analgesic into the lumbar epidural space.(3) It was first used in 1949, it became the gold standard after its popularity in the early 80s, and sine then it's the only method that provides complete analgesia without maternal or fetal sedation. (1) 
To achieve the best pregnancy outcome in proper pain management, depends on women's understanding of the nature of labor pain.(1)

Previous studies in developing countries have shown that the issue regarding labor analgesia revolves around awareness, acceptability and availability of analgesia for labor, while Issues in high-income countries are focused on the choice of methods and complications,(4)

In this study, the aim is to assess the knowledge and attitude of Saudi women toward painless labor, and misconception about the risks and complications.

\section{Population \& Sample of the Study:-}

The study population includes all Saudi women. A sample of (386) women was selected randomly, the next table shows their properties according to their personal data.

Table 1:- Distribution of the sample study to the demographic data.

\begin{tabular}{|c|c|c|c|c|}
\hline \multicolumn{2}{|l|}{ Variable } & $\mathrm{N}$ & $\%$ & P-value \\
\hline \multirow[t]{3}{*}{ Age (years) } & $18-30$ & 169 & 43.8 & \multirow[t]{3}{*}{$0.000 *$} \\
\hline & $31-40$ & 103 & 26.7 & \\
\hline & $>40$ & 114 & 29.5 & \\
\hline \multirow[t]{5}{*}{ Educational Level } & No education & 9 & 2.3 & \multirow[t]{5}{*}{$0.000 *$} \\
\hline & Primary & 11 & 2.8 & \\
\hline & preparatory & 17 & 4.4 & \\
\hline & Secondary & 62 & 16.1 & \\
\hline & College degree & 287 & 74.4 & \\
\hline \multirow[t]{2}{*}{ current work } & Housewife & 183 & 47.4 & \multirow[t]{2}{*}{0.309} \\
\hline & Employed & 203 & 52.6 & \\
\hline
\end{tabular}

Chi-squared test: *Significant at 0.01

It is clear from the previous table that almost $44 \%$ of the participants were between (18-30) years, almost $27 \%$ of them were between (31-40) years old, and almost $30 \%$ of them were more than (40) years old.

And their distribution according to educational level, almost $74 \%$ of them were college degree, almost $16 \%$ of them were secondary, almost $4 \%$ of them were preparatory, and almost $3 \%$ of them were primary. And their distribution according to current work, almost 53\% of them were employed, while almost $47 \%$ of them were Housewife. The next figure concludes all the previous results.

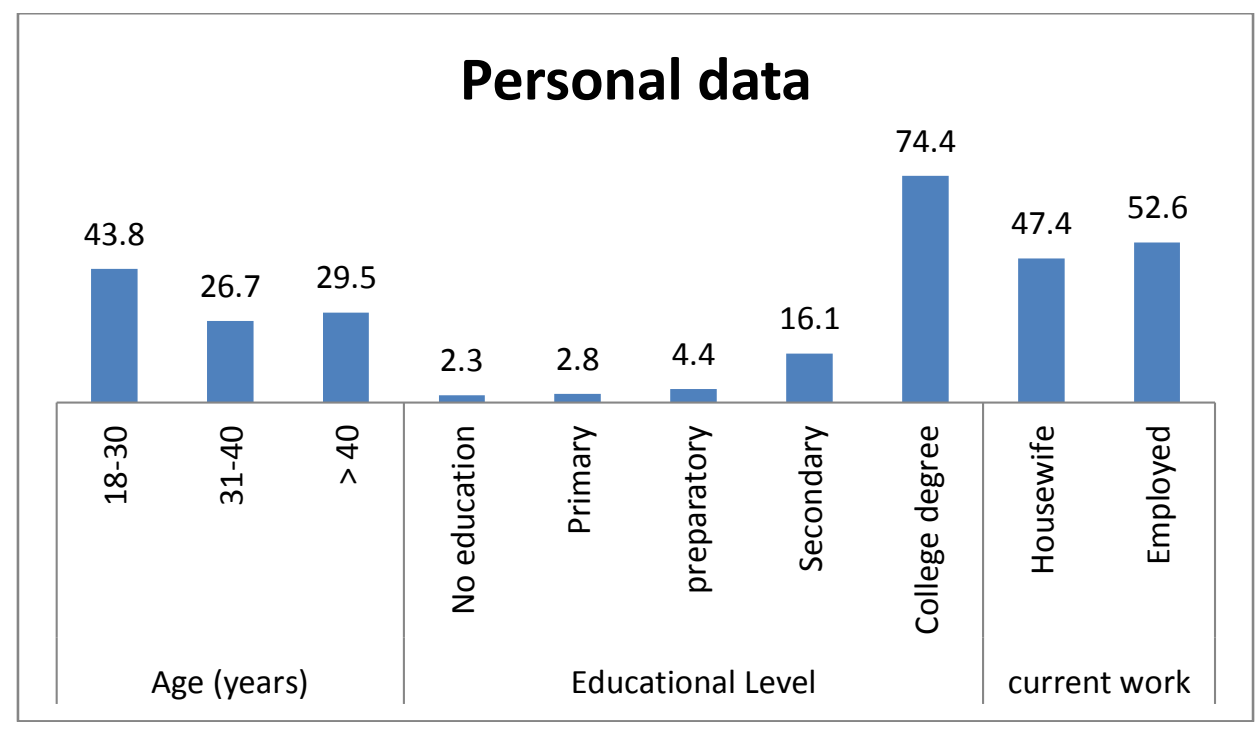

Figure 1:- Distribution of the sample study to the demographic data. 


\section{The study tool:-}

The questionnaire was the study tool, it was prepared by the researcher with the help of specialists and experts in this field, and the questionnaire includes a part of questions on socio-demographic data as age, educational level, and current work.

While the second section consisted of (19) questions to assess the knowledge and attitude of Saudi women toward painless labor, and misconception about the risks and complications.

\section{Statistical methods:-}

The statistical analysis program (SPSS v.22) was been used in the study in data entry and analysis, with the use of necessary statistical methods to achieve the objectives of the study. The following statistical methods were used:

1. Frequencies.

2. Percentages.

3. Graphs.

4. Chi-square test.

\section{Results:-}

The following table shows the participants' distribution according to the number of pregnancies and the number of births, noting that almost $69 \%$ of Saudi women have been pregnant more than once, almost $16 \%$ once pregnant, while almost $16 \%$ have never had pregnancy.

Almost $66 \%$ have already given birth more than once, almost $18 \%$ have already given birth only once, and almost $16 \%$ have never given birth.

Table 2:- shows the participants' distribution according to the number of pregnancies and the number of births.

\begin{tabular}{|c|c|c|c|c|}
\hline & & $\mathrm{N}$ & $\%$ & P-value \\
\hline \multirow[t]{3}{*}{ Number of pregnancies } & Once & 60 & 15.5 & \multirow[t]{3}{*}{$0.000^{*}$} \\
\hline & More than once & 266 & 68.9 & \\
\hline & I have never so & 60 & 15.5 & \\
\hline \multirow[t]{3}{*}{ Number of births } & Once & 68 & 17.6 & \multirow[t]{3}{*}{$0.000^{*}$} \\
\hline & More than once & 256 & 66.3 & \\
\hline & I have never so & 62 & 16.1 & \\
\hline \multicolumn{2}{|l|}{ Total } & 386 & 100.0 & \\
\hline
\end{tabular}

The following table shows the participants' distribution according to whether they were anesthetized in their previous births, noting that almost $31 \%$ of them were anesthetized in their previous births, while almost $69 \%$ were not anesthetized in their previous births.

Table 3:- shows the participants' distribution according to whether they were anesthetized in their previous births.

\begin{tabular}{|l|l|l|}
\hline The answer & N & $\%$ \\
\hline Yes & 119 & 36.7 \\
\hline No & 205 & 63.3 \\
\hline Total & 324 & 100.0 \\
\hline
\end{tabular}

The following diagram shows the participants' distribution according to their hearing about the epidural analgesia.

The vast majority of Saudi women (95\%) have heard about epidural analgesia. 


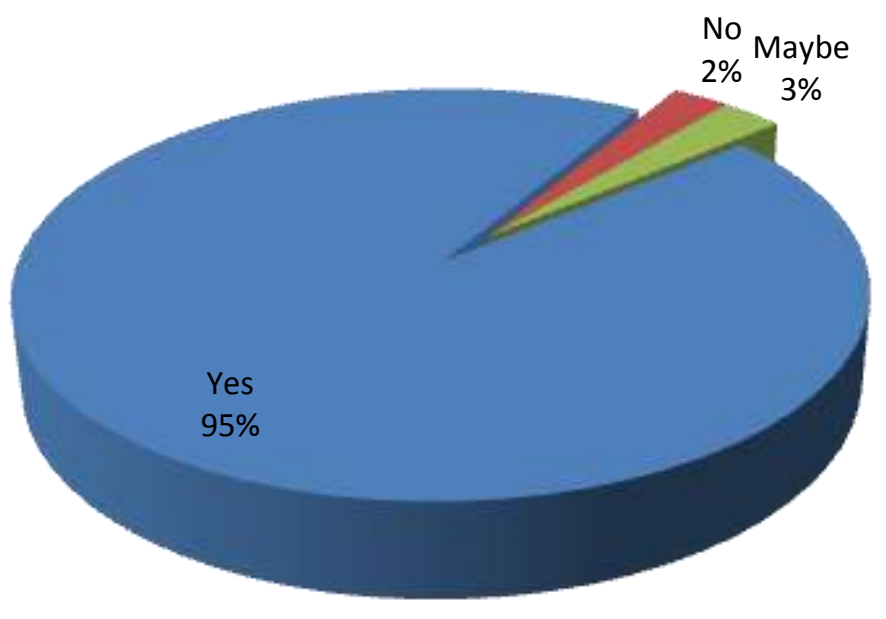

Figure 2:- shows the participants' distribution according to their hearing about epidural analgesia.

The following diagram shows the participants' distribution according to the source of their information about epidural analgesia, where we note that almost $67 \%$ of them heard about epidural analgesia through friends and relatives, and almost $16 \%$ of them know about epidural analgesia through previous labour experience, and almost $8 \%$ of them heard about epidural analgesia Through the media, and almost $2 \%$ through books.

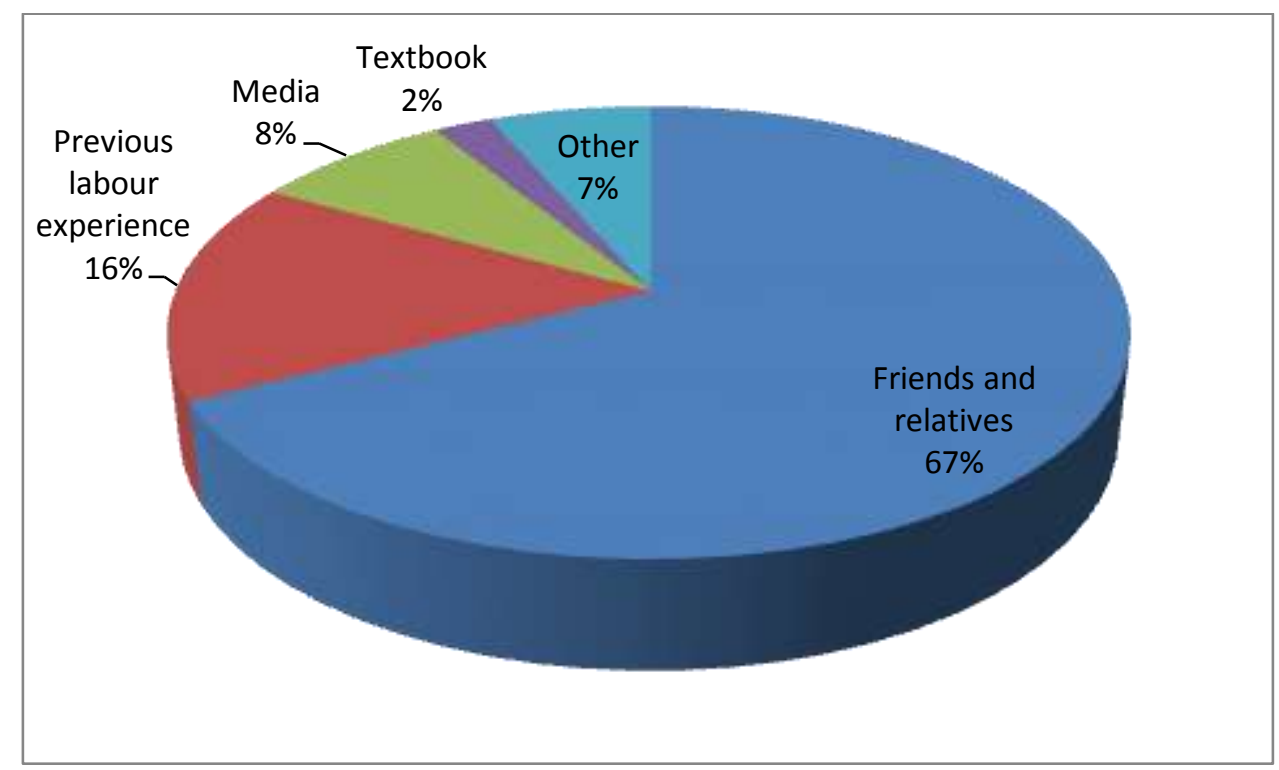

Figure 3:- shows the participants' distribution according to the source of their information about epidural analgesia.

The following table shows the participants' distribution according to whether they recommend pregnant women with epidural analgesia, noting that almost $50 \%$ of them advise women with epidural analgesia, while almost 50\% do not recommend it. 
Table 4:- shows the participants' distribution according to whether they recommend pregnant women with epidural analgesia.

\begin{tabular}{|l|l|l|}
\hline The answer & N & $\%$ \\
\hline Yes & 183 & 50.1 \\
\hline No & 182 & 49.9 \\
\hline Total & 365 & 100.0 \\
\hline
\end{tabular}

The following table shows the participants' distribution according to whether the doctor discussed the available birth options. Where we note that almost $61 \%$ of women did not have their doctor to discuss ways of birth available to them, while almost $39 \%$ of women by the doctor to discuss ways of birth available to them.

Table 5:- shows the participants' distribution according to whether the doctor discussed the available birth options.

\begin{tabular}{|l|l|l|}
\hline The answer & N & $\%$ \\
\hline Yes & 151 & 39.1 \\
\hline No & 235 & 60.9 \\
\hline Total & 386 & 100.0 \\
\hline
\end{tabular}

The following table shows the participants' distribution according to preferred mode of delivery for them, where we note that almost $54 \%$ of them prefer baby's delivery, almost $35 \%$ prefer to epidural analgesia, $7 \%$ prefer elective cs, almost $6 \%$ prefer epidural, almost $4 \%$ prefer breathing exercises.

Table 6:- shows the participants' distribution according to preferred mode of delivery for them,

\begin{tabular}{|l|l|l|}
\hline The answer & $\mathrm{N}$ & $\%$ \\
\hline epidural analgesia & 136 & 35.3 \\
\hline Elective cs & 28 & 7.3 \\
\hline Breathing exercise & 14 & 3.6 \\
\hline natural childbirth & 208 & 53.9 \\
\hline Total & 386 & 100.0 \\
\hline
\end{tabular}

The following table shows the participants' distribution according to their expectation of pain from childbirth using the epidural analgesia, where almost $41 \%$ of them expect mild pain, almost $27 \%$ expect moderate pain, almost $9 \%$ expect severe pain, while almost $24 \%$ expect no pain.

Table 7:- shows the participants' distribution according to their expectation of pain from childbirth using the epidural analgesia.

\begin{tabular}{|l|l|l|}
\hline The answer & $\mathrm{N}$ & $\%$ \\
\hline No pain & 92 & 23.8 \\
\hline Mild & 157 & 40.7 \\
\hline Moderate & 103 & 26.7 \\
\hline Severe & 34 & 8.8 \\
\hline Total & 386 & 100.0 \\
\hline
\end{tabular}

The following table shows the participants' distribution according to their view on the need to use anesthesia in childbirth, where almost $62 \%$ of them believe that anesthesia should be used in childbirth to relieve pain, almost $20 \%$ believe that anesthesia should be used in childbirth to relieve stress, and almost $17 \%$ That anesthesia should be used in childbirth to enjoy the experience, and almost $2 \%$ believe that anesthesia should be used in childbirth to increase confidence.

Table 8:- shows the participants' distribution according to their view on the need to use anesthesia in childbirth.

\begin{tabular}{|l|l|l|}
\hline The answer & $\mathrm{N}$ & $\%$ \\
\hline To relieve pain & 238 & 61.7 \\
\hline To relieve stress & 76 & 19.7 \\
\hline To feel confident & 6 & 1.6 \\
\hline To enjoy the experience & 66 & 17.1 \\
\hline Total & 386 & 100.0 \\
\hline
\end{tabular}

The following table shows the participants' distribution according to their point of view about the need not to use anesthesia in childbirth, where we note that almost $42 \%$ of them believe that you should not use anesthesia in childbirth because birth is a natural process, and almost $25 \%$ of them believe that you should not use anesthesia in childbirth because anesthesia will cause complications, and almost $21 \%$ believe that anesthesia should not be used in 
childbirth because anesthesia will make labor longer, and almost $13 \%$ believe that anesthesia should not be used in childbirth because anesthesia will affect the baby.

Table 9:- shows the participants' distribution according to their point of view about the need not to use anesthesia in childbirth.

\begin{tabular}{|l|l|l|}
\hline The answer & $\mathrm{N}$ & $\%$ \\
\hline Labor is a natural process & 161 & 41.7 \\
\hline It will make labor longer & 79 & 20.5 \\
\hline Will cause complications & 96 & 24.9 \\
\hline It will affect the baby & 50 & 13.0 \\
\hline Total & 386 & 100.0 \\
\hline
\end{tabular}

The following table shows the participants' distribution according to their view on the expected effect of the use of anesthesia on the child, where we note that almost $11 \%$ of them expect that anesthesia affect the baby's breathing, and almost $6 \%$ expect that anesthesia affects bonding, and almost $2 \%$ expect That anesthesia affects breastfeeding, while almost $64 \%$ expect that there is no effect from the use of anesthesia on the child.

Table 10:- shows the participants' distribution according to their view on the expected effect of the use of anesthesia on the child

\begin{tabular}{|l|l|l|}
\hline The answer & $\mathrm{N}$ & $\%$ \\
\hline It will affect the baby's breathing & 42 & 10.9 \\
\hline It will affect bonding & 22 & 5.7 \\
\hline It will affect breast feeding & 9 & 2.3 \\
\hline Other & 67 & 17.4 \\
\hline There is no effect & 246 & 63.7 \\
\hline Total & 386 & 100.0 \\
\hline
\end{tabular}

The following table shows the participants' distribution according to their view on the expected effect of the use of anesthesia on childbirth, where $30 \%$ believe that it will lead to future health problems for women, almost $28 \%$ believe it will reduce mothers ability to push, almost $22 \%$ It will stop contractions.

Table 11:- shows the participants' distribution according to their view on the expected effect of the use of anesthesia on childbirth.

\begin{tabular}{|c|c|c|}
\hline The answer & $\mathrm{N}$ & $\%$ \\
\hline It will stop contractions & 84 & 21.8 \\
\hline Make the labor unnatural & 10 & 2.6 \\
\hline Prolong the duration of birth & 44 & 11.4 \\
\hline Affect the mothers ability to push & 108 & 28.0 \\
\hline Increase the chances of the using peat & 19 & 4.9 \\
\hline Increase Caesarean section & 7 & 1.8 \\
\hline Will lead to future health problems for women & 114 & 29.5 \\
\hline Total & 386 & 100.0 \\
\hline
\end{tabular}

The following table shows the participants' distribution according to their view on the concerns of anesthesia related to women's health. $49 \%$ believe that it causes backache, almost $19 \%$ believe that it causes a headache, almost $14 \%$ believe that it causes numbness, almost $12 \%$ believe that it may be a bad experience, and almost $6 \%$ have fears of waking up during operation.

Table 12:- shows the participants' distribution according to their view on the concerns of anesthesia related to women's health

\begin{tabular}{|l|l|l|}
\hline The answer & $\mathrm{N}$ & $\%$ \\
\hline Concern about headache & 72 & 18.7 \\
\hline Concern about backache & 190 & 49.2 \\
\hline Concern about numbness & 55 & 14.2 \\
\hline Relative bad experience & 45 & 11.7 \\
\hline Don't want to awaked during operation & 24 & 6.2 \\
\hline
\end{tabular}


Total

386

100.0

The following chart shows the most important reasons preventing women from taking anesthesia during childbirth from the point of view of Saudi women. The most important reasons are the lack of awareness of the patient, the lack of awareness of the medical staff, the fact that anesthesia is not a primary cause of childbirth.

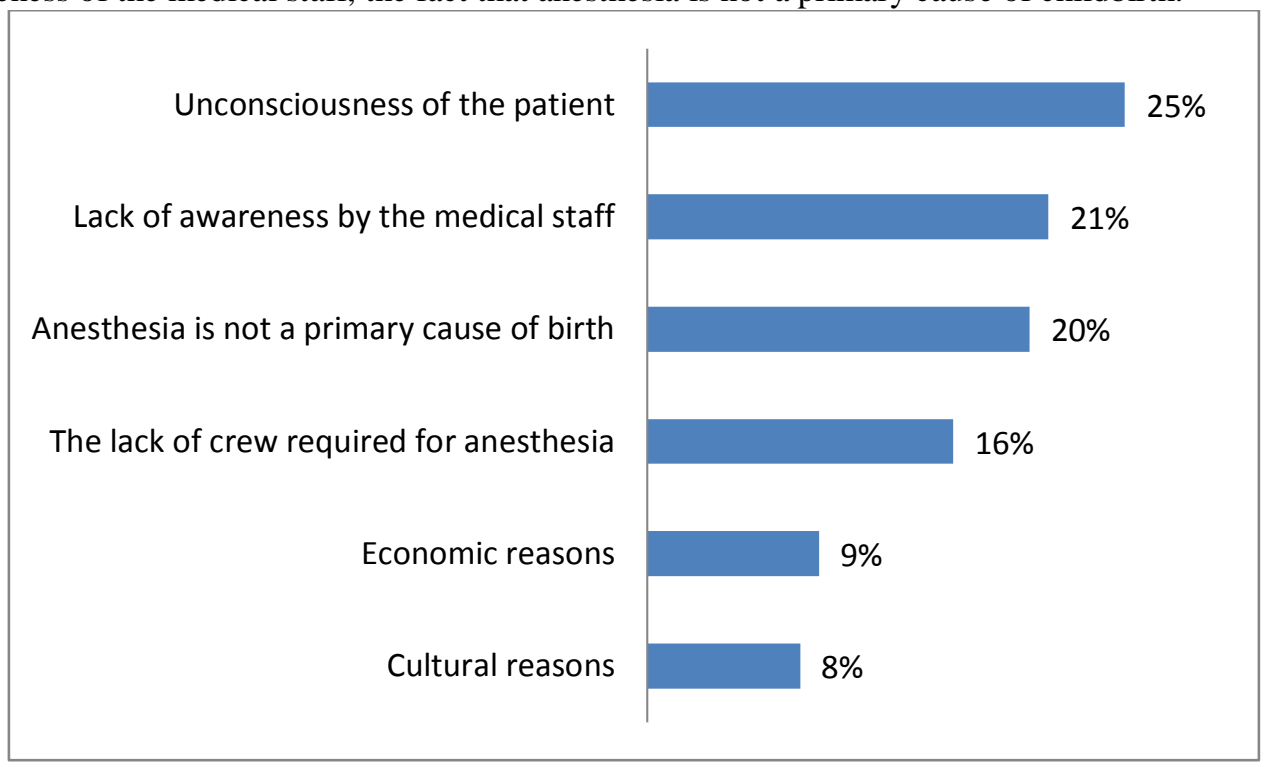

Figure 3:- shows the most important reasons preventing women from taking anesthesia during childbirth from the point of view of Saudi women.

The following table shows the participants' distribution according to their view of the maximum benefit of anesthesia during childbirth. We note that almost $52 \%$ of the respondents believe that the benefit of anesthesia during childbirth will be achieved if the woman has a previous experience of childbirth, while almost $48 \%$ believe that the benefit of anesthesia during childbirth will be realized if this is the first birth of a woman.

Table13:- shows the participants' distribution according to their view of the maximum benefit of anesthesia during childbirth

\begin{tabular}{|l|l|l|}
\hline The answer & $\mathrm{N}$ & $\%$ \\
\hline If this is the first birth of a woman & 184 & 47.7 \\
\hline If the woman has a previous experience of childbirth & 202 & 52.3 \\
\hline Total & 386 & 100.0 \\
\hline
\end{tabular}

The following table shows the participants' distribution according to the fears that prevent them from using anesthesia in their future births, where we note that almost $35 \%$ believe that there will be no effect or benefit from the use of anesthesia in their future births, while almost $32 \%$ prefer the experience of natural delivery as it is, almost $10 \%$ believe that The use of anesthesia in childbirth will increase the chances of Caesarean deliveries in the future.

Table 14:- shows the participants' distribution according to the fears that prevent them from using anesthesia in their future births.

\begin{tabular}{|l|l|l|}
\hline The answer & $\mathrm{N}$ & $\%$ \\
\hline wanted to experience natural childbirth & 123 & 31.9 \\
\hline against the will of God & 28 & 7.3 \\
\hline it would harm the baby & 27 & 7.0 \\
\hline will love their baby more & 4 & 1.0 \\
\hline Will increase the chances of cesarean deliveries in the future & 37 & 9.6 \\
\hline mothed do not work. & 135 & 35.0 \\
\hline refusal by family. & 32 & 8.3 \\
\hline Total & 386 & 100.0 \\
\hline
\end{tabular}


The following table shows the participants' distribution according to whether they plan to use any of the anesthetics in their next births, noting that almost $38 \%$ of them plan to use any of the anesthetics in their future births, while almost $32 \%$ do not plan for it.

Table15:- shows the participants' distribution according to whether they plan to use any of the anesthetics in their next births.

\begin{tabular}{|l|l|l|}
\hline The answer & N & $\%$ \\
\hline Yes & 146 & 37.8 \\
\hline No & 124 & 32.1 \\
\hline Perhaps & 116 & 30.1 \\
\hline Total & 386 & 100.0 \\
\hline
\end{tabular}

The following table shows the participants' distribution according to decision-making authority on the use of anesthesia in childbirth, noting that almost $46 \%$ of Saudi women make the decision about anesthesia in childbirth with the help of the husband, almost $26 \%$ with the help of the family, almost $10 \%$ with the help of Girlfriends and almost $18 \%$ Other.

Table 16:- shows the participants' distribution according to decision-making authority on the use of anesthesia in childbirth

\begin{tabular}{|l|l|l|}
\hline The answer & $\mathrm{N}$ & $\%$ \\
\hline Husband & 177 & 45.9 \\
\hline Family & 102 & 26.4 \\
\hline Girlfriends & 37 & 9.6 \\
\hline Other & 70 & 18.1 \\
\hline Total & 386 & 100.0 \\
\hline
\end{tabular}

\section{Discussion:-}

The knowledge and attitudes regarding labour pain and labour pain relief among pregnant women are not known clearly, especially in developing countries. For the majority of women, the childbirth is a painful experience (5). The deficiency of awareness and misunderstanding regarding safety, acceptability and availability of pain relief options are considered to be the major causes why women do not receive adequate pain relief in many low and middle income countries (6). Therefore this study aimed to assess the knowledge and attitude of Saudi women toward painless labor, and misconception about the risks and complications.

The present study included 386 women, the majority of them had undergone more than one previous delivery, almost $36.7 \%$ of the participants availed epidural analgesia in their previous deliveries. While, In a study in Karachi only $19 \%$ availed epidural analgesia, due to fears and misconceptions regarding the epidural analgesia(7). And in a study conducted in Nigeria among 124 mothers, only 4\% could remember using any way of pain relief in their previous pregnancy, this low rate of pain relief using is attributed it to fear of side effects on baby or self while some were not even sure of its benefits (8).Also, in Uganda among multiparous women about $88 \%$ did not have labour analgesia in their previous deliveries, due to many views and beliefs that's expressed by the women regarding labour analgesia, also religion and culture play a role in made the decisions regarding labour analgesia (9).

At the present study the mothers showed a good level of knowledge about the epidural analgesia. Whereas, $95 \%$ of mothers at this study heard about the epidural analgesia to reduce the pain of labor. Minhas found that $76 \%$ of mothers were aware of epidural analgesia as a method of labor pain relieving (7).

Friends and relatives were the most common source of information regarding epidural analgesia to reduce the pain of labor, followed by previous labour experience, then the media , and books reported by $67 \%, 16 \%, 8 \%$,and $2 \%$ respectively. This finding like Minhas et al. finding whose found that $64 \%$ had heard about epidural analgesia from friends or relatives (7). Also, Nabukenya et al. whose found that among those who had knowledge of labour analgesia, the most common source of information was friends and relatives. Few got information from the previous labour, even fewer from media and literature (9). 
About half of participated women at the present study have positive attitude towards epidural analgesia. This percentage is much lower than what was found by Thakur et al. whose reported that $96.7 \%$ of expectant mothers had positive attitude towards epidural analgesia (10).

The obstetrician should explain to the woman during follow-up during pregnancy, the available birth options, and ways to reduce labor pains. But, It is striking that the majority of women in this study did not discuss available birth options with the doctor. This findings like Mugambe et al. findings in South Africa that women who had been pregnant before, in general were not told what to expect during labour (16). Hodnett found that a woman's satisfaction regarding labour depends on the quality of her relationship with her caregivers and included good rapport, communication and information, and the freedom with which she can express about her feelings (17).

There are many ways to relieve pain of labour. The pharmacological ways known are epidural analgesia, parenteral opioids, paracervical block and nitrous oxide. Some of the non-pharmacological ways are transcutaneous electrical nerve stimulation, breathing exercises, acupressure, sterile water injections, acupuncture, immersion bath, hydrotherapy, audio-analgesia, hypnosis, aromatherapy, labour support, relaxation and massage. The suitable labour pain relief method sould be effective and safe, and should not overlap with labour or the parturient mobility $(5,11)$.

The natural childbirth was the most preferred method of birth among women in this study by $53.9 \%$. This high proportion of mothers who prefer normal childbirth without pain relief is due to the common belief among women that Labor is a natural process. Dehghanpisheh et al. found that almost 32\% preferred the natural childbirth as a method of birth (12).

All the medication which used by woman during labor enters the bloodstream of child as well through the umbilical cord. This includes anesthetics and pain-relieving drugs that delivered through epidurals. But anesthetics do not have a stronger effect on the baby than other painkillers that might be considered for use during childbirth. Regarding the side effect of neuraxial labor analgesia on mothers, includes pruritus and hypotension, maternal hyperthermia, nausea and vomiting, epidural analgesia also associated with a longer labor and increased rates of operative vaginal delivery (13-15). In the current study, women showed good level of knowledge regarding the side effects of analgesics during childbirth, on the baby and mother, where most mothers reported that pain relief during childbirth had no effect on the baby's health. They showed a variety of responses about the side effects of maternal pain during childbirth.

\section{Conclusion:-}

This study demonstrated that there was a good level of knowledge about the epidural analgesia among Saudi women. However, there was low prevalence of epidural analgesia using among Saudi mothers. Generally, there was positive attitude among Saudi women towards epidural analgesia. But, natural childbirth sill the preferred method of birth.

\section{Recommendation:-}

1. Conduct awareness campaigns among women, clarify the effectiveness of the epidural analgesia in reducing labor pains.

2. Doctors should clarify to pregnant women during follow-up, all available delivery methods, and all available ways to reduce labor pains.

3. Distribution of leaflets to pregnant women in various health facilities, including different delivery methods, available ways of reducing labor pains, and their potential effects on both mother and infant. 


\section{References:-}

1. Apondi, Christine. "A survey of the knowledge attitude and practice regarding epidural labor analgesia among obstetricians at the Kenyatta National Hospita" IUNIVERSITY OF NAIROBI (2012).

2. Laleh Dehghanpisheh, Golnar Sabetian, Zohre Faghirzade, and Mohammad Ali Sahmeddini. "KNOWLEDGE AND ATTITUDE OF IRANIAN PARTURIENT WOMEN TOWARDS PAINLESS LABO". A QUALITATIVE SURVEY. Professional Medical Journal . 2015, Vol. 22 Issue 7, p966-972. 7p.

3. Shammi Karn, Hong Yu, Sourabh Karna, Liqin Chen, and Dongyan Qiao Affiliation(s). "Women's Awareness and Attitudes towards Labor Analgesia Influencing Practice between Developed and Developing Countries" Department of Obstetrics and Gynecology, Zhong Da Hospital, Medical School, Southeast University, Nanjing, China. Nepal Medical College, Kathmandu University, Kathmandu, Nepal. DOI: 10.4236/arsci.2016.42007

4. Mary T. Nabukenya, Andrew Kintu, Agnes Wabule, Mark T Muyingo and Arthur Kwizera " Knowledge, attitudes and use of labour analgesia among women at a low-income country antenatal clinic " Accepted: 24 June 2015Published: 7 July 2015

5. James, Joyce Nilima, Kunder Samuel Prakash, and Manickam Ponniah. "Awareness and attitudes towards labour pain and labour pain relief of urban women attending a private antenatal clinic in Chennai, India." Indian Journal of anaesthesia 56.2 (2012): 195.

6. McCauley, Mary, Catriona Stewart, and Birhanu Kebede. "A survey of healthcare providers' knowledge and attitudes regarding pain relief in labor for women in Ethiopia." BMC pregnancy and childbirth 17.1 (2017): 56.

7. Minhas, Mohammed Raheel, et al. "Knowledge, attitude and practice of parturients regarding Epidural Analgesia for labour in a university hospital in Karachi." J Pak Med Assoc 55.2 (2005): 63-6.

8. Ogboli-Nwasor, Elizabeth O., and Sunday E. Adaji. "Between pain and pleasure: Pregnant women's knowledge and preferences for pain relief in labor, a pilot study from Zaria, Northern Nigeria." Saudi journal of anaesthesia 8.Suppl 1 (2014): S20.

9. Nabukenya, Mary T., et al. "Knowledge, attitudes and use of labour analgesia among women at a low-income country antenatal clinic." BMC anesthesiology 15.1 (2015): 98.

10. Thakur, Manisha, Nidhi Sagar, and Pooja Tandon. "Knowledge and attitude regarding epidural analgesia among expectant mothers." International Journal of Reproduction, Contraception, Obstetrics and Gynecology 6.5 (2017): 1929-1931.

11. Karn, Shammi, et al. "Women's awareness and attitudes towards labor analgesia influencing practice between developed and developing countries." Advances in Reproductive Sciences 4.02 (2016): 46.

12. Dehghanpisheh, Laleh, et al. "Knowledge and Attitude of Iranian Parturient Women Towards Painless Labor." Professional Med J22.7 (2015): 966-72.

13. Wong, Cynthia A. "Advances in labor analgesia." International journal of women's health 1 (2009): 139.

14. KAMALI, ALIREZA, et al. "COMPARISON OF LABOR PHASES IN PAINLESS DELIVERY WITH EPIDURAL ANALGESIA AND ENTONOX ADMINISTRATION."

15. Leeman, Lawrence, et al. "The nature and management of labor pain: part II. Pharmacologic pain relief." American family physician 68.6 (2003): 1115-1120.

16. Mugambe, J. M., et al. "Knowledge of and attitude towards pain relief during labour of women attending the antenatal clinic of Cecilia Makiwane Hospital, South Africa." South African Family Practice 49.4 (2007): 1.

17. Hodnett, Ellen D. "Pain and women's satisfaction with the experience of childbirth: a systematic review." American Journal of Obstetrics \& Gynecology 186.5 (2002): S160-S172. 